\title{
Left-handedness and Stigmatization in Africa: Implications for Parents and Teachers
}

\author{
Ayanniyi B Alhassan* \\ Department of Education, Sule Lamido University, Nigeria
}

Submission: November 13, 2018; Published: November 29, 2018

*Corresponding author: Ayanniyi B Alhassan, Department of Education, Sule Lamido University, Kafin Hausa, Jigawa State, Nigeria

\begin{abstract}
Left-handedness dominance is usually in the sense of being a minority condition affecting about $10 \%$ of the world's population. There are also a variety of even rarer conditions on the handedness spectrum, including mixed-handedness, and ambidextrousness. The 'right' and 'left' in cultural confines that are generally sustainable in an anthropological sense are on offer. Cultural understanding and cultural awareness are a vital part of international communication. Knowing using the left hand is considered rude in African cultures is just the beginning of positive non-verbal communication. In many African cultures and in many cultures of the world, there has been a history of discrimination and many stigmas associated with left-handedness; while it has been celebrated in other cultures where they are esteemed. In the light of the foregoing, implications for parents and teachers are on offer.
\end{abstract}

Keywords: Left-handedness; Stigmatization; Parents; Teachers

\section{Introduction}

Left-handed men and women have existed for more than 30,000 years [1]. For centuries, individuals have been in search for the answers to why people prefer left- hand over the right- hand and why the left- hand is such a minority. It is a curious quirk of human nature that most of us $(90 \%)$ prefer using our right hand, while a minority of around $10 \%$ prefer using their left - a ratio that has remained remarkably stable across cultures and ethnicities for several thousand years [1]. It is still a mystery on several levels: Why do left-handers exist in the first place? And what is so special about the right side of the world? [2]. Although lefthand humans are in the minority, the fact that they exist suggest there are certain advantages to variations in handedness across a population. The evidence for the determination of left-handedness has been attributed to intrauterine factors, physiological, genetic and environmental, and data of various sorts have been used in attempts to establish one fact or another [3].

In medieval times lefties were thought to be in league with the devil and considered less intelligent than right-handers. In the Middle Ages, the left-hander lived in danger of being accused of practicing witchcraft. The Devil himself was considered a southpaw, and he and other evil spirits were always conjured up by left-handed gestures [4]. Then modern research discovered cross wiring of our brains controls which hand we favor and that left-handers may be more artistic, are better tennis players and grow up quicker than right-handers [5]. Handedness is ability in using one hand more skillfully than, and in preference to, the other [6]. Handedness is a better (faster or more precise) performance or individual preference for use of a hand, known as dominant hand [7].
Handedness is not a discrete variable (left or right), but a continuous one that can be expressed at levels between strong left and strong right [8]. Being left-handed implies preferring using the left hand for a variety of tasks, reaching, throwing, pointing, and catching. Handedness is observed quite early in human development. Tests of fetuses (using-ultra sound) show $92 \%$ sucking their right thumbs, a figure that mirror prevalence in the adult population [9]. There are four types of Handedness: Left -handedness, Right-handedness; Mixed-handedness, and Ambidexterity [10]. Left-handedness is somewhat more common among men than among women [11].

\section{Right and Left in African Culture}

The 'right and left' in cultural confines that are generally sustainable in an anthropological sense was offered much earlier [12]:

a. Right side associated with men, left with women.

b. Right equivalent to 'good', left to 'bad (inferior).

c. Right connected with good luck, left with misfortune, or correspondingly, happenings on the right side being good omens, those on the left bad omens.

d. Left representing fortune; right misfortune.

e. Right side preferred, left considered inferior.

f. Color associations with right and left.

g. Right and left denoting orientation. Cultural understanding and cultural awareness are a vital part of international communication. Knowing using the left-hand 


\section{Global Journal of Archaeology \& Anthropology}

is considered rude in African cultures is just the beginning of positive nonverbal communication.

\section{Stigmatization of Left-Handedness}

The human hand has long carried cultural baggage, and yet we still struggle to unclutched from it the myths and the realities. In many African cultures and in many cultures of the world, there has been a history of discrimination and many stigmas associated with left-handedness. The stigma of 'dirty' lefties has persisted due to societal mores in Africa. Throughout much of Africa, and in the Middle East and so on you get this thing - you eat your food with your right hand, and you cleanse your body and do the unclean parts with your left hand. Whatever you do, do not touch African food with your left hand. That is not an uncommon set of beliefs and social processes throughout Africa [12].

Left- Handedness is extensively disapproved in most cultures: African tribes and ancient pre-Christian superstition also equate left with bad! At the very least, being left-handed was considered unnatural and peculiar in antiquity. There may well be a deeply social or biological instinctive reason why left-handedness has traditionally disturbed some. Perhaps it is merely a form of xenophobia, a kind of fear based on subconsciously off-putting physical movement of those that are left-handed. The deficits come not from being left-handed, but from being treated as if there is a deficit. For Southpaws themselves- the affectionate term for lefties- this biological peculiarity has been everything from a source of stigma to a point of pride.

Left- Handedness is an interesting, and sometimes troubling phenomenon. It is if you are a student trying to sit in a righthanded desk; or trying to use a right-handed potato peeler or right-handed scissors, or a right-handed mouse- or any of the right-handed devices. It is if you get bad marks from your teacher because of handwriting. For example, in Vietnam, schools officially require pupils to write with their right hand and some teachers of Grade 1 where writing is taught) would implement that rule by deducting points from tests written by the left hand. The word left in English comes from the Anglo-Saxon word lyft, which means weak or broken.

The Oxford English Dictionary defines Left-handed as meaning cropped, defective, awkward, clumsy, inept, characterized by underhanded dealings, ambiguous, doubtful, questionable, illomened, inauspicious, and illegitimate [13]. Phrases in English suggest a negative view of Left-handedness. For instance, a lefthanded compliment is an insult. A 'Left-handed marriage' is not a marriage but an adulterous sexual liaison, as in a Left-handed honeymoon with someone else's husband. A 'Left-handed wife' is actually a mistress [14]. It is if you analyze terminology such as: Left-handed compliment, left-wing, out in left field, or in French, gauche; German, linkish; Russia, Levja; Latin, Sinistra- none of which are especially complimentary.

\section{Left-Handedness in Africa}

In Africa, being left-handed is considered weird, and lefties have a lot to deal with. Africans look at left-handers with disdain, and quite often reject left-handed handshakes, receiving money from a left hand and collecting things from an outstretched left hand. In African culture, using the left hand has no place at all. Study in Africa, using broadly comparable methods, found that $7.9 \%$ of people in Abidjan, Ivory Coast and $5.1 \%$ of the people in Khartoum, Sudan were left-handed [15]. In some African tribes, a candidate to be chief can be turned down entirely on the grounds of left-handedness. Catholic school teachers used to tell students that left-handedness was "the mark of the Beast". Among the LeftHand Drive countries in Africa are Burundi, Cameroon, Central African Republic and Chad. In such countries, the traffic is on the right side, but the driver sits on the left.

Left-handedness has been celebrated in other cultures, where the lists of enduring empire leaders such as Alexander the Great, Julius Caesar, Napoleon Bonaparte, Leonardo Da Vinci-one of the finest minds in human history-, Albert Einstein-celebrated as the quintessential modern genius, juggernaut corporation leadersBill Gates, Warren Buffett, Henry Ford, John Rockefeller, and movie stars are esteemed. Even six out of seven past presidents of the United States have been left-handed. Uhuru Kenyatta who was elected President of Kenya in March 2013 and reelected in 2018, is a left-handed writer. So are Bernard Bembe-Tanzania's Foreign Minister, Namadi Sambo, Kashim Shettima, Babatunde Fashola, Oluwarotimi Akeredolu, Adams Oshiomhole-Nigerian Leaders; Professors Zaynab Alkali and Ayanniyi Alhassan. Shaykh Muhammad Rajab was a left-hander and a courageous Sudanese horseman. The Vice-President of Liberia, Moses Blah is lefthanded.

But the stigma of "sinister", "dirty" lefties has persisted due to societal mores in Africa. In Ghana, there is a general taboo on lefthand use: Giving, receiving, eating, and drinking with the left hand are considered rude by virtually all members of the community. A significant proportion of the people also consider pointing by the left hand to be rude. Pointing, here, includes both gestures that indicate a direction toward a location. Consequently, they avoid hand pointing by the left-hand in face- to-face interaction, especially with superiors and strangers [16]. Malawians cited their views that "left hand is less skilled and less powerful than the right ones" as the main reasons for forcing left-handers to convert. Among students, teachers and parents, $75 \%$ said the left hand should not be used to perform habitual activities, and $87.6 \%$ of these believed left-handers should be forced to switch dominant hands. Parents and close relatives are most responsible for impressing these beliefs upon their children [17].

There is Left-Hand Learning in South Africa- the only company in that country dedicated to left-hand learners, the parents and educators! From cognate experience, the company knows how challenging fine motor skills can be for some children and, for some left-handers, it can be even more so. Those critical skills such as cutting, drawing, letter and number formation are so important in the development of South African children and indeed of all children. Often, children need to be taught from a lefthand perspective. Without understanding and knowledge a child 


\section{Global Journal of Archaeology \& Anthropology}

may struggle unnecessarily learning the basic fine motor skills. There are at least 250 ethnic groups in Nigeria and 526 different languages. In Nigeria, people are inclined to view left-handedness as worst and as a sign of evil or at best an expectantly curable adversity. The left hand is still demonized as unlucky, evil, clumsy, and so on. Not only that, it is seen as disrespectful to accept or give someone anything with the left- hand [18].

The left-hand is associated with disrespect and bad manners in arguably many (if not all) Nigerian cultures. It is the hand usually used to perform acts that are otherwise irritating to a person. This could be the picking of a dirty object, washing or wiping the backside after defecation. The Yoruba people of SouthWest Nigeria and West Africa go to the extent they dubbed any child who gives directions to his/her father's house as "omo ale " which means bastard " only a bastard will give directions to his/ her father's house with the left hand" : This shows the extent at which the Yoruba people esteems ethics in their culture. Also, learning institutions (particularly primary schools) in Yoruba communities take part in the quest to kick down the wrong use of the left hand, particularly in writing, among their pupils/students.

It is to be noted that the indigenous religions do not condemn the left hand because it serves important purposes. For example, the religion of If consider the left hand sacred as it is mostly used for important purposes and rites such as looking into someone's future by looking into his/her left palm; holding of sacred religious items and so on. But today, the condemnation of the left hand in Yoruba land has begun to fade, but at a very low rate, and consequently, some Yorubas have preferred to call the left hand "owo alaafia" which literally means "hand of peace" instead of "owo osi", the original Yoruba word for left hand. It is imperative to note that other ethnic groups in Nigeria and the world at large also share this belief attached to the left hand, but in distinct ways. In most schools across Nigeria, teachers complain that lefthanded children are slow learners and give them special work to do. They tried as much as possible to see if such children could use their right hands by forcing/punishing them [19].

In Senegal, the left hand is considered dirty. No one uses their left hand as their dominant hand (for writing, eating, and so on) - any children who might otherwise choose to use their left hand are quickly corrected. The left hand is dirty because, here, there is no toilet paper. Left-handedness is very uncommon in Somalia. Fire-burning is a procedure where a stick from a special tree is heated till it glows and then applied to the skin in order to cure the illness (left-handedness).

\section{Left-Handedness in Senegal}

In Senegal, the left hand is considered dirty. No one uses their left hand as their dominant hand (for writing, eating, and so on)- any children who might otherwise choose to use their left hand are quickly corrected. The left hand is dirty because, here, there is no toilet paper. Rather, people use water and their left hand to clean themselves after using the bathroom. Thus, it is socially unacceptable to use that same hand to do anything else.
Handshakes are done right-handed. You use your right hand to eat (most people eat with their hands).

\section{Left-Handedness in Uganda}

In Uganda, historically it was considered evil and "Stan-like" to ably execute task with your left-hand. In traditional religious act, the devil was said to sit on God's left-hand, which has made the left-hand dawned one. In addition, when one was left-handed, they will be called a witch, ultimately leading to their hand been burned at the stake. Although the modern world seems to have moved on from superstition, stereo types attached to using the left-hand have persisted in some societies. That is why some teachers and parents still insist that a child must learn to use the right hand. All this must end because left-handedness is neither a disease nor a disability. It is a lifestyle, based on an individual's brain arrangement. A child who ended up left-hand should not be forced to do the right hand, says Bernard Bogere, the mastermind behind Keep Left Uganda Foundation (KLUF). In association with the Education Ministry, Thakerere \& Kyanbogo Universities is making efforts to ensure that the left-hand is kept at least for those who have not yet been forced to lose it. KLUF is also advocating for enough sitting and writing space for left-hand writers in primary Schools, the level when a child start learning to write. Bogere in his study discovered, among other findings that there are about One Million Two hundred and fifty thousand $(1,250,000)$ lefthand writers and two hundred and fifteen thousand six hundred $(215,600)$ stammering children in Primary School across Uganda, representing $16 \%$ and $2 \%$ respectively of the current Primary School population.

\section{Left-Handedness in Zimbabwe}

In Zimbabwe, in many cases, left-handed people are forced to change to right hand at early stages of their lives. For those who manage to escape family and social pressure to switch from left to right, life in this right-handed world is not easy, but tiring and painful. For example, something as simple as writing, is one of the challenges they have learnt to live with. Where right-handed people drag the pen behind from left to the right of the page, for left handers, it is the opposite.

Most left-handed children face challenges when using the remote controls and joysticks for games as they too, are made for right-hand people. Left-handers clicks are opposite, a right-click is a left-click and a left-click is a right-click. Some children learn to accommodate that at an early stage. There are several other tools that just make their life miserable. Opening or closing a zip or tying shoe laces are not as easy as right-handed people imagine. Using simple tools like scissors or sickle is a nightmare, as these tools are designed for right-handed people. For example, a scissors are made in such a way that blades push slightly and tightly together for a sharper and straight cut of an object.

In Zimbabwe, in many cases, left-handed people are forced to change to right hand at early stages of their lives. For those who manage to escape family and social pressure to switch from left to right, life in this right-handed world is not easy, but tiring and 
painful. For example, something as simple as writing, is one of the challenges they have learnt to live with. Where right-handed people drag the pen behind from left to the right of the page, for left- handers, it is the opposite.

\section{Left-Handedness in Ethiopia}

Cultural etiquette in Ethiopia is different from elsewhere in the world! It is best to avoid using your left hand while eating injera, hand shaking or shopping. Using your left-hand is often considered rude.

\section{Implications for Parents}

Parents should acknowledge a child's Left-handedness by making it look like a blessing rather than a curse. For example, left-handed men and women have been known to have the ability to think outside the box and this has made it easy for them to solve problems both in school and in life situations. It is imperative for parents to build their boys/girls confidence with good company. Remind your boy/girl that some of the most powerful men and women to have ever lived and are living are left-handed such as Ronald Regan, Gerald Ford, George H.W. Bush, Bill Clinton and Barack Obama. There are also many Left-handed innovators, musicians, guitarists, and athletes such as Jimi Hendrix, Babe Ruth, Leornardo Da Vinci, Marie Curie, Judy Garland and Oprah Winfrey, Professors who are left-handed- Zaynab Alkali, Weis Daniel, Ayanniyi Alhassan, Xu Chenyang, Raghuran Rajan, and Bernard Maxum, amongst others.

As parents, you have a duty to help your boy/girl to adapt to his/her left-handedness by showing him/her how to do the simple, everyday things using the left hand such as tying their shores, learning his/her dance steps. Parents should be gentle when giving physical guidance so that your boy/girl will be able to adjust well. It is important for parents to teach their boy/girl to write. Writing is the biggest hurdle for many left-handed boys and girls. In English writing and several other languages, writing is done from left to right. Though this is a common practice, it benefits right-handed people whose hand does not run across what they write, because their hand moves in front of the text. A left-handed person may smudge what he writes. In Vietnam, schools officially require students to write with their right hands and some teachers of Grade 1 (where writing is taught) would implement that rule by deducting points from test written by the left hand. The way a left-handed person writes letters is different from a right-handed person. Let your boy/girl know that it is okay to cross the J to T right-left instead of left-right. Parents also need to make effort to help their son/daughter appreciate that people have their own views: when they try to correct him/her, s/he should politely tell them that he is a natural lefty, that God has made her/him that way, and that her/his left hand is the right for all religious, moral and practical purposes. Parents can also assist their left-handed boys and girls by doing the following:

a. Placing their table settings according to their handedness.
b. Providing left-handed scissors.
c. Help them find the easiest ways to handle paper and pencil.

d. Assuring that teachers and parents/caregivers treat their lefthanders appropriately.

e. Not dwelling on their children's non-right handedness. Making it through childhood life suffering the taunts of all the right-handed children because a left-handed child could not conform to the right-hand world can last a life-time. If the psychological obstacles that they face were not bad enough, a left-handed person must live in a world that was built from the ground up by right-handed people for right-handed people.

\section{Implications for Teachers}

It is essential for every teacher to be trained to recognize the different needs of left-handed boys and girls. Teacher Training and the National Curriculum should be overhauled so that lefthanders are given the space and correct implements to achieve the same results as right-handed pupils. A simple set of guidelines should be introduced as a Module into the Mandatory Teacher Training that considers the slightly different needs of pupils who favor their left hand. There are a few simple things teachers can do in the classroom to make a dramatic difference to lefthanders in their early years at school and avoid problems as they develop through the education system. These are:

a. Sitting a left-handed child on the left side of writing areas so they do not bump elbows with the child next to them.

b. Demonstrating a correct writing grip and encouraging an effective writing position.

c. Having left-handed scissors available and know how to use them.

d. It is important that teachers understand that lefthanders will form some letters in a different direction to right handed.

Handwriting is the foundation of all writing and when it is well handled, the primary school pupils are equipped for all the writing skills they will require to function at all the levels of the education system [20-22].

\section{References}

1. McManus C (2002) Right Hand and Left-Hand. Harvard University Press, USA.

2. Frayer DW, Lozano M, Bondioli L (2012) More Than 5,000 Years of Right-Handedness in Europe. Laterality, 17: 51-69.

3. Franklin JL (2008) The Sound of One Hand Clapping: Meditations on Sinistrality. Paper presented at the meeting of the Chicago Literary Club, USA.

4. TIME (1969)

5. McManus C (2002) Right Hand and Left-Hand. Harvard University Press, USA. 
6. Alhassan AB (2011) Concise Modern Dictionary of Educational Psychology. Zaria, Tamaza Publishing Company, Nigeria.

7. Holder MK (2012) What does handedness have to do with brain lateralization (and who cares?).

8. Annet M (2002) Handedness and Brain Asymmetry. Psychological Press.

9. Lalumiere MI (2002) Sexual orientation and handedness in men and women: a meta-analysis. Psychological Bulletin 126: 575-579.

10. Holder MK (2012) What does Handedness have to do with Brain Lateralisation (and who cares?).

11. Papadatou-Pastou M, Munafo $T$ (2008) Sex differences in lefthandedness: A meta-analysis of 144 studies. Psychological Bulletin 134(5): 677-5,699.

12. Wile IS (1934) Handedness, Right and Left.

13. Coren S (1992) The Left-hander syndrome: The causes of lefthandedness. Detroit, Michigan, USA.

14. McManus C (2002) Right Hand and Left-Hand. Harvard University Press, USA.

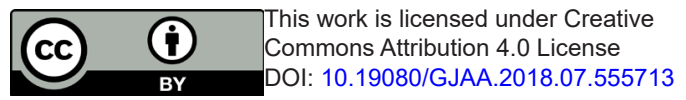

15. Coren S (1992) The Left-hander syndrome: The causes of lefthandedness. Detroit, Michigan, USA.

16. Coren S (1992) The Left-hander syndrome: The causes of lefthandedness. Detroit, Michigan, USA.

17. McManus C (2002) Right Hand and Left-Hand. Harvard University Press, USA.

18. Kita S, Essegbey J (2001) How a taboo on the use of left-hand influences gestural practice. Gesture, 1(1): 73-95.

19. Zverev YP (2006) Cultural and Environmental Pressure Against Lefthand Preference in Urban and Rural Malawi. Brain \& Cognition 3: 295 303.

20. Alhassan AB (2017) Left-Handedness, The Bible and The Qu'ran: Implications for Parents and Teachers. Research \& Review; Journal of Educational Studies, USA, 3(1): 19- 26.

21. Ogunmola-Omilani T (2017) Naturally Left-Hand Children Should Be Managed- Experts. Leadership.

22. Wilson, Sir Daniel (1891) The Right-hand: Left-handedness. Macmillan \& Company, London, UK.

\section{Your next submission with Juniper Publishers will reach you the below assets}

- Quality Editorial service

- Swift Peer Review

- Reprints availability

- E-prints Service

- Manuscript Podcast for convenient understanding

- Global attainment for your research

- Manuscript accessibility in different formats

( Pdf, E-pub, Full Text, Audio)

- Unceasing customer service

Track the below URL for one-step submission https://juniperpublishers.com/online-submission.php 